\title{
wIntolerance - Uma plataforma para integração de pessoas com restrições alimentares
}

\author{
Leonardo Braga Genuino', Hedo Eccker da Silva Júnior¹, Rodrigo Remor \\ Oliveira $^{1}$ \\ ${ }^{1}$ Instituto Federal de Educação, Ciência e Tecnologia Sul-rio-grandense (IFSul) \\ 93.216-9120 - Sapucaia do Sul-RS - Brasil \\ \{leonardobgenuino, hedojunior\} @gmail.com, \\ remoresapucaia.ifsul.edu.br.br
}

Resumo. Este artigo descreve o wintolerance, um projeto que visa prestar assistência às pessoas que sofrem de restrições alimentares, visto que somente no Brasil, cerca de 10 milhões de pessoas sofrem com este problema. wintolerance é uma plataforma colaborativa que permite os usuários trocarem receitas que atendam às suas restrições alimentares, assim como avaliarem de maneira detalhada elas. Além disso, possibilita que os usuários encontrem e avaliem restaurantes que fornecem pratos específicos para essas pessoas. Com o projeto pretende-se divulgar e auxiliar milhões de pessoas que sofrem com este tipo de problema.

\begin{abstract}
This article describes [APPLICATION NAME], a project that aims to give assistance to people that suffers from alimentary restrictions, since only in Brazil, about 10 million people suffers from this kind of problem. [APPLICATION NAME] is a collaborative platform that allows the users to exchange recipes that caters to their alimentary restrictions, as well as make detailed evaluations of those. Besides that, is possible that the users find and rate restaurants that offers specific plates. The project aims to publicize and help millions of people who suffer from this type of problem.
\end{abstract}

\section{1.}

\section{Introdução}

Os conceitos de computação ubíqua estão cada vez mais presentes na sociedade, por meio da popularização dos dispositivos móveis e dos avanços científico-tecnológicos [Satyanarayanan 2001]. Dispositivos como smartphones e tablets fazem parte do cotidiano de um número cada vez maior de pessoas, acompanhando-as em sua rotina, tais dispositivos são capazes de coletar e monitorar informações acerca das atividades que seu usuário faz. Então, a computação ubíqua [Weiser 1991] alinhada com o constante uso de dispositivos móveis abre espaço para a exploração de novas aplicações da computação ubíqua, aplicando ela no cotidiano do usuário. Nesse âmbito, os Location Based Services (LBS) são serviços que integram a localização ou posição do dispositivo móvel com outras informações para prover valores adicionais ao usuário [Spiekermann 2004], podendo ser utilizado em diversos tipos de aplicações, como redes sociais e jogos.

Muitas pessoas ainda desconhecem a diferença entre intolerância e alergia alimentar. As reações alérgicas ocorrem quando o sistema imunológico reconhece um alimento que contém uma substância que possa fazer mal ao indivíduo [Nunes 2012]. Nesses casos, o corpo tende a dar uma resposta imunológica mais rápida, que pode variar de 15 minutos até 48 horas [Gasparin, F. et al., 2010]. De 15 minutos até 6 
horas após a ingestão do alimento, um intolerante à lactose, por exemplo, pode ter sintomas como urticária, vermelhidão na pele e diarreia [Vieira 2004, Barros 2012]. E, em casos de alergia muito grave à certo alimento, a ingestão do mesmo pode causar dificuldades respiratórias, diminuição da pressão arterial e do oxigênio cerebral, podendo levar a vítima à morte [Filho 2014], sendo que, entre 100 e 125 pessoas morrem por ano nos Estados Unidos em decorrência de uma alergia alimentar [Sanz 2001]. Em uma manifestação mais tardia, os sintomas podem aparecer como cólicas, dores abdominais, assim como no aumento na quantidade de fezes e alguns problemas respiratórios.

Pessoas com restrições alimentares sofrem cada dia mais com a falta de acessibilidade [Porto, C. et al., 2005] quanto à sua alimentação [Tumas 2008], seja pela falta de opções de alimentos alternativos, pelo difícil preparo de alimentos alternativos, ou pela falta de cuidado e conhecimento sobre a área por parte de terceiros. Quando se trata de crianças, o problema se torna ainda mais grave [Bricks 1994], visto que elas, muitas vezes, não têm o conhecimento da intolerância ou alergia que sofrem, ou então de quais alimentos devem comer, evitar, dentre outras complicações. De acordo com METZ e BURKS (2009), aproximadamente 6\% das crianças em grupos de 0 a 5 anos de idade sofrem de alguma alergia ou intolerância alimentar. Se a restrição não for diagnosticada desde cedo, os alérgenos poderão trazer consequências graves a curto prazo, em casos de alergias, ou a longo prazo, em casos de intolerâncias. Dada a falta de interligação entre estabelecimentos e clientes, o crescente número de intolerantes e alérgicos [Pérez-Machado, M. et al., 2003], e as dificuldades que permeiam o dia a dia destes, fica clara a necessidade de algo que possibilite a conexão entre todo o grupo de pessoas com restrições alimentares e restaurantes e demais estabelecimentos que atendem esse público. Surge assim o seguinte questionamento: como prover acessibilidade para pessoas com restrições alimentares de uma maneira ágil, precisa e objetiva?

O presente trabalho apresenta uma plataforma colaborativa de integração e ajuda mútua entre pessoas com restrições alimentares. A plataforma, denominada wIntolerance, possui os seguintes objetivos:

\section{Colaboração:}

-Permitir que usuários cadastrem receitas de acordo com suas restrições alimentares, para que outros usuários possam avaliar essa receita, deste modo, contribuindo para a construção da comunidade da plataforma;

-Se tornar uma "vitrine" para que proprietários de restaurantes que atendem pessoas com restrições alimentares, onde eles poderão cadastrar seus estabelecimentos e serem avaliados.

\section{Facilidade:}

-Fornecer uma ferramenta de pesquisas de forma rápida e intuitiva, onde os usuários aprendam a utilizar a funcionalidade rapidamente;

-Utilizar a localização do usuário para exibir os restaurantes na proximidade que se encaixam no seu perfil;

-Facilitar a avaliação de receitas e restaurantes para fornecer mais comodidade aos usuários.

\section{Trabalhos relacionados}

Entre os trabalhos estudados, encontram-se diversos projetos que envolvem pessoas com restrições alimentares, porém nenhum deles realmente realiza uma conexão entre 
pessoas com restrições alimentares com restaurantes, e com outras pessoas de uma forma colaborativa. Deste modo, para a comparação entre os trabalhos estudados, foi utilizado o Modelo 3C's de Colaboração (Comunicação, Cooperação e Coordenação) [Pimentel, M. et al., 2006]. Para classificar foram levados em conta quesitos que poderiam ser encaixados em um ou mais dos 3C's. Avaliação no app (Cooperação e Comunicação) avalia se a plataforma permite aos usuários avaliarem seus itens, Abrangência (Coordenação) considera a gama de restrições que o aplicativo fornece apoio, Comunicação entre usuários (Comunicação e Cooperação), Receitas (Coordenação), Estabelecimentos (Coordenação), LBS (Coordenação) leva em conta se o aplicativo utiliza ou não os conceitos de Location Based Services.

Quadro 1. Comparação entre trabalhos relacionados.

\begin{tabular}{|c|c|c|c|c|}
\hline & My Holy Food & $\begin{array}{l}\text { Safe } \\
\text { Food }\end{array}$ & Celiaquitos & Achei sem Glúten \\
\hline Avaliações no app & $\begin{array}{l}\text { Avaliação } 5 \\
\text { estrelas + } \\
\text { comentários }\end{array}$ & & $\begin{array}{c}\text { Avaliação } 5 \\
\text { estrelas + } \\
\text { comentários }\end{array}$ & \\
\hline Abrangência & $\begin{array}{l}\text { Glúten Vegan } \\
\text { Carboidrato } \\
\text { Açúcar Lactose }\end{array}$ & $\begin{array}{c}\text { Vegan } \\
\text { Lactose } \\
\text { Glúten }\end{array}$ & Glúten & Glúten \\
\hline $\begin{array}{l}\text { Comunicação } \\
\text { entre usuários }\end{array}$ & & & $\begin{array}{l}\text { Forúm de } \\
\text { Unsuários }\end{array}$ & \\
\hline Receitas & & $\mathrm{x}$ & & \\
\hline Estabelecimentos & Restaurantes & & Restaurantes & $\begin{array}{c}\text { Restaurantes } \\
\text { Lojas }\end{array}$ \\
\hline LBS & $x$ & & $\mathrm{X}$ & $x$ \\
\hline
\end{tabular}

Como pode ser visto no Quadro 1, o MyHolyFood possui avaliações com comentários e fornece informações acerca do item avaliado para a comunidade. O MyHolyFood tem o diferencial de apresentar restaurantes que oferecem pratos com pouco açúcar e carboidratos. Em contrapartida, o Achei Sem Glúten é o menos completo deles, prestando suporte apenas a pessoas com restrições relacionados ao glúten, tendo como único diferencial a disponibilidade de acesso a lojas e não apenas a restaurante, como as demais plataformas.

O único que apresenta interações colaborativas é o Celiaquitos. Na plataforma, existe um fórum moderadamente ativo de usuários, onde eles trocam informações acerca de restaurantes seguras para sua alimentação. Este é um ponto favorável ao Celiaquitos, porém ele é muito limitado, prestando suporte apenas a pessoas com intolerância a glúten e apresentando apenas restaurantes em sua plataforma.

O SafeFood é o único que disponibiliza receitas em sua plataforma, algo que é de extrema relevância, pois possibilita aos usuários terem acesso a uma maior gama de receitas que eles podem fazer no dia a dia. Ele também presta suporte a vegetarianos e veganos, atendendo assim pessoas que tem não somente restrições ligadas a problemas de saúde, mas também a mudanças do cotidiano. Porém, o SafeFood não possui nenhuma forma de avaliação de seus itens. 
Dentro os trabalhos relacionados, é possível verificar que nenhum apresenta uma plataforma colaborativa para ampla publicação e avaliação de receitas e restaurantes, em conjunto com uma grande abrangência de restrições alimentares. É visível também a necessidade de se realizar isso de forma colaborativa, para que os usuários possam se ajudar de forma dinâmica e que a comunidade do aplicativo aumente progressivamente. Considerando-se motivos apresentados, nenhum dos trabalhos se mostra como uma plataforma colaborativa com uma ampla abrangência de restrições. A fim de contornar as limitações apresentadas pelos demais trabalhos, apresenta-se na Seção 3 a plataforma colaborativa wIntolerance, cujo objetivo é a integração e ajuda mútua entre pessoas com restrições alimentares.

\section{Metodologia}

\subsection{Pesquisa e planejamento}

Com o presente trabalho pretende-se ampliar o auxílio às pessoas que sofrem com alimentação restritiva, identificando problemas e disponibilizando o devido apoio, através de um aplicativo para dispositivos móveis. Para identificar melhor a necessidade do público-alvo foi realizada uma pesquisa de campo, voltada a pessoas com restrições alimentares. A pesquisa foi dividida em 3 seções, na primeira foram perguntadas as informações pessoais do indivíduo, como: restrição que possui, idade e cidade onde reside. A segunda seção do questionário foi direcionada a perguntas acerca de restaurantes, como com qual frequência eles vão a restaurantes, o que eles procuram em um restaurante e qual o preço máximo que poderiam pagar em algo voltado para sua restrição. Por fim, a última seção foi feita em relação a receitas, perguntando qual a possibilidade de eles usarem uma plataforma que facilite o acesso a receitas que atendem às suas restrições alimentares e quais as maiores dificuldades que enfrentam no dia a dia.

A fim de identificar a viabilidade de uma plataforma voltada para público intolerante/alérgico, a seguinte pergunta foi criada: "Você utilizaria uma plataforma (sites ou aplicativos) que facilitaria o acesso às receitas que atendam suas restrições alimentares?". Onde 78,9\% das pessoas responderam positivamente, desta forma, tivemos certeza que era necessária a criação de algo que atendesse essas pessoas.

Outra pergunta relevante para o projeto foi: "Você encontra dificuldade em localizar restaurantes que tenham pratos voltados às pessoas com restrições alimentares?". Por meio deste foi possível o quão necessário é a disponibilidade de algo que faça a conexão entre clientes e restaurantes, dado que $81 \%$ das pessoas responderam "Sim".

A pesquisa teve um total de 42 entrevistados, captados durante a apresentação do projeto em feiras e pela divulgação do projeto na escola e na rede de contatos dos desenvolvedores. Após o apuramento dos resultados, foi possível analisar diversas funcionalidades que deveriam ser implementadas no aplicativo, assim como alguns detalhes e características que a plataforma deveria possuir.

Com base nas pesquisas realizadas sobre computação ubíqua e sobre os aplicativos existentes na área de acessibilidade foram definidos os requisitos da plataforma. A seguir, os requisitos do sistema são apresentados:

- Requisito 1: Cadastro de perfil, receitas e restaurantes;

- Requisito 2: Busca dinâmica por nome, localidade (caso seja um restaurante), restrição atendida, tipo de receita; 
- Requisito 3: Avaliação de receitas e restaurantes, onde se pode avaliar quesitos específicos para cada um;

- Requisito 4: Mapa que apresenta restaurantes próximos com base na localidade do usuário.

Os requisitos apresentados foram pensados visando prover a maior facilidade aos usuários, no âmbito de cadastrar e pesquisar receitas. Por exemplo, o Requisito 3 é muito importante para o aplicativo, pois é por meio dele que o usuário colaborará com a plataforma. O Requisito 2 também será bastante utilizado pelos usuários da plataforma, pois a busca dentro do aplicativo é feita para o usuário encontrar o que ele realmente deseja, informando o máximo de detalhes possíveis, seja uma receita ou um restaurante.

\subsection{Desenvolvimento}

\subsubsection{A plataforma wIntolerance}

O wIntolerance é possui dois componentes chamados de wInServer e wInApp. A função do wInServer é a de manuseio de dados, persistindo, entregando, atualizando e deletando informações quando necessário. O wInServer consiste em um Web Service REST, programado em Java utilizando frameworks como JAX-RS e Jersey, que se conecta com um banco de dados relacional MySQL por meio do framework JPA Hibernate. O wInApp, entretanto, é uma plataforma desenvolvida para dispositivos Android que utiliza esses serviços para que haja a interação com o usuário final e assim o mesmo tenha grande controle sobre suas ações e o que pode ou não ser feito no aplicativo. O wInApp utiliza diversas bibliotecas disponíveis para Android para otimizar o produto final e o tempo de produção, talvez a mais importante delas sendo a biblioteca Retrofit, utilizada para fazer requisições para o wInServer, por meio do protocolo HTTP com conteúdo JSON. O wInApp é representado na Figura 5 pela aplicação Android e o wInServer pelo RESTFul Web Service.

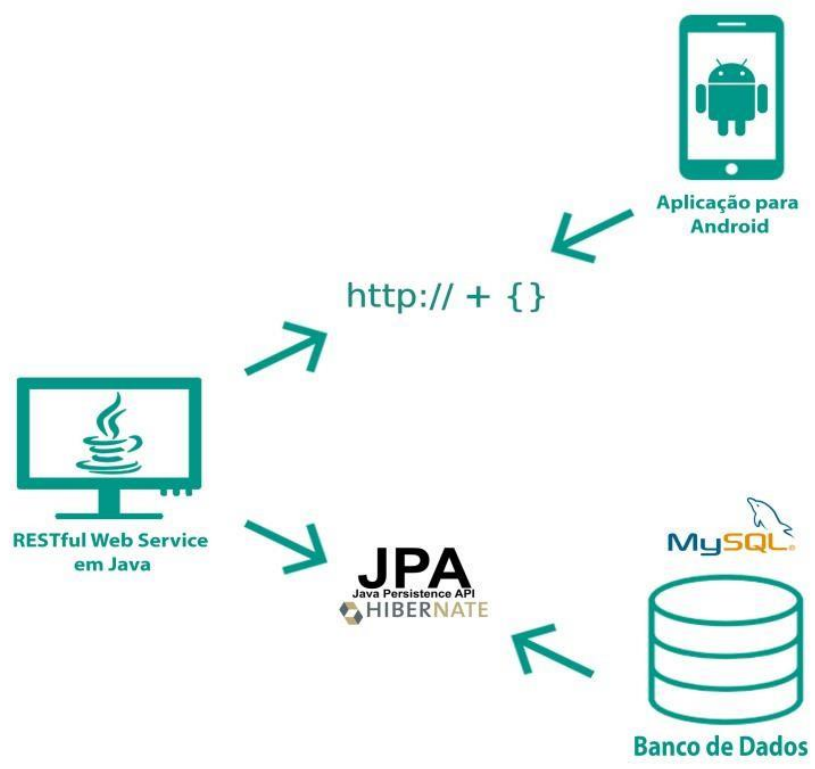

Figura 5. Arquitetura do Sistema 


\subsubsection{O componente wInServer}

O wInServer é uma aplicação Java que provê os dados necessários para consumo do wInApp. Para facilidade de explicação, pode-se dividir o wInServer em três camadas principais:

A camada Entity, é onde se encontram os POJOs, classes Java que servem para representar os principais componentes do sistema. Cada classe POJO tem suas anotações do framework Hibernate, estas que por sua vez definem o comportamento deste objeto ao ser mapeado para uma entidade relacional. Por exemplo, uma receita cadastrada no aplicativo pode abranger várias restrições alimentares diferentes. A representação disso em código seria que o POJO "Receita" pode ter vários POJOs "Restrição", este relacionamento sendo definido pela anotação “@OneToMany” do Hibernate.

A segunda camada, é denominada DAO e é onde operam as classes que efetuam operações no banco de dados, manipulando os POJOs da camada Entity para que possa alterar, deletar e adicionar novas entidades ao banco de dados impondo antes quaisquer regras necessárias para isso. Nesta camada se encontram as classes DAO, que são classes específicas para acesso e alteração de dados das entidades supracitadas. Estas classes são responsáveis também pela transformação dos POJOs em DTOs, que são objetos de transporte de dados que servem para que os POJOs não tenham contato direto com o usuário final e também para levarem apenas os dados necessários para visualização e uso no wInApp. As classes DTO foram mapeadas utilizando anotações JAX-B que possibilitam a configuração dos objetos JSON que serão entregues pelo WebService para as requisições do wInApp.

Para garantir a qualidade do software, foram utilizados os frameworks Mockito e jUnit para a criação de testes unitários, que são altamente importantes para que haja total certeza do funcionamento dos métodos dos serviços inclusive em casos extremos, os chamados edge cases. A utilização dos testes foi de suma importância desde o início da implementação da plataforma, pois se um teste retorna resultado negativo é sinal de que algo deve ser alterado no código-fonte, para que não haja futuros problemas.

A camada chamada Services é onde foi configurado o Web Service REST do wIntolerance. O Web Service foi desenvolvido utilizando os frameworks JAX-RS e Jersey, que definem um conjunto de regras de serviços RESTful. Nesta camada foram definidas as Controllers, que são as rotas disponíveis no Web Service para consumo de dados.

\subsubsection{O componente wInApp}

O aplicativo do wIntolerance foi desenvolvido em Android nativo, partindo da API 19, tem suas bases de estilo seguindo o padrão Material Design do Google e também utilizando bibliotecas para otimização de produção. Para o consumo dos dados oriundos do wInServer, é utilizada a biblioteca Retrofit (2013). Esta biblioteca possibilita, por meio de interfaces, configurar quais as rotas que se deseja consumir do WebService, quais parâmetros enviar e quais cabeçalhos definir para cada requisição. A biblioteca utiliza da biblioteca GSON do Google para transformar os objetos JSON vindos de requisições em objetos Java e vice-versa.

Para a localização de Restaurantes nas redondezas dos usuários é utilizada a biblioteca Google Maps, que tem ótima integração com Android e provê informações bastante completas sobre muitos locais requisitados. Esta biblioteca também é utilizada em outros pontos do aplicativo, como no cadastro de um novo Restaurante, quando o 
mapa é utilizado para que o Usuário selecione o endereço do restaurante. Além destas bibliotecas também são utilizadas outras, de menor tamanho e impacto geral, para auxílio nas configurações de estilo e disposição de elementos no aplicativo. Uma outra biblioteca cabível de menção é a Compressor, que serve para comprimir imagens para um tamanho em disco bem menor sem perda visível de qualidade. O objetivo geral da interface visual do aplicativo é dispor ao usuário uma interface bastante leve e dinâmica, baseando-se nos conceitos de Material Design para Android para definição de paletas de cores, sombreamentos, contrastes e afins. A facilidade de uso é um dos fatores mais norteadores do projeto.

\section{Aspectos de avaliação}

A validação e avaliação do sistema se dará por meio de um cenário de teste em ambiente controlado em conjunto com questionários e entrevistas, a fim de averiguar a aceitação do wIntolerance. Para tal, será utilizado o modelo estendido da Unified Theory Of Acceptance and Use of Technology, conhecido como Teoria Unificada de Aceitação e Usa da Tecnologia (UTAUT2). O UTAUT2 utiliza as variáveis Intenção de Comportamento e Intenção de Uso, sendo que ambos levam em consideração outras variáveis, como Expectativa de Desempenho, Influência Social, Motivações Hedônicas, Habito. [Venkatesh, V. et al., 2012 apud Faria, L. et al., 2014]. Assim sendo, os dados coletados via os questionários e entrevistas serão avaliados utilizando esses dois critérios, por meio de tais informações será possível identificar quais pontos do aplicativo necessitam de algum aprimoramento e o nível de aceitação que ele tem.

\section{Resultados e discussão}

No wIntolerance, os usuários podem primeiramente acessar sem fazer cadastro, podendo apenas visualizar as receitas e restaurantes, caso queiram publicar e avaliar os itens do aplicativos, devem se cadastrar utilizando um e-mail e senha, onde os mesmos passarão por validações, por exemplo se o e-mail está no formato exemplo@exemplo.com ou se a senha possui no mínimo seis caracteres. Após realizar o cadastro, o usuário poderá aprimorar seu perfil, adicionando uma foto e suas restrições.
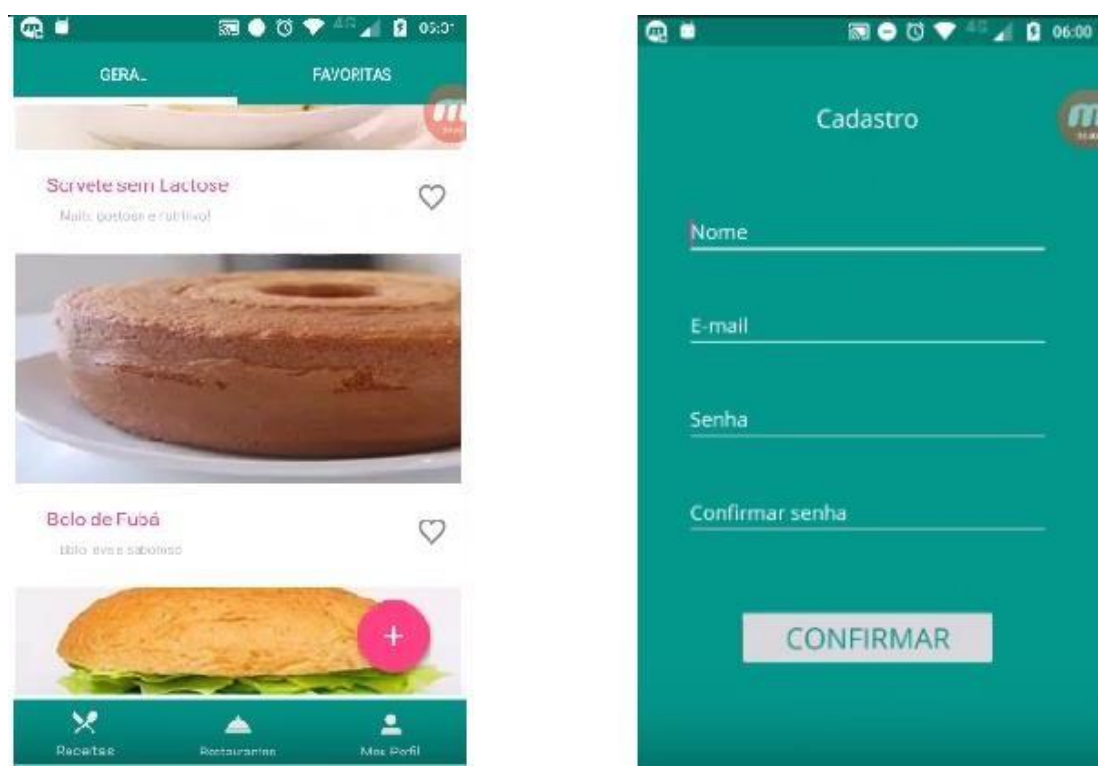

Figura 6. Tela inicial e tela de cadastro de perfil. 
Como pode ser visto na Figura 6, na tela inicial são apresentadas as receitas mais bem avaliadas do momento, onde o usuário pode optar por clicar para abrir mais detalhes sobre a receita clicada ou favoritar a mesma. É possível também acessar outras seções como os restaurantes ou o perfil do usuário. O usuário também pode cadastrar receitas (Figura 7). Para isso, ele deve preencher os campos, adicionando o nome, a foto, a categoria dessa receita, quais restrições ela abrange, seu tempo de preparo e rendimento e também, especificar seu passo a passo e ingredientes.
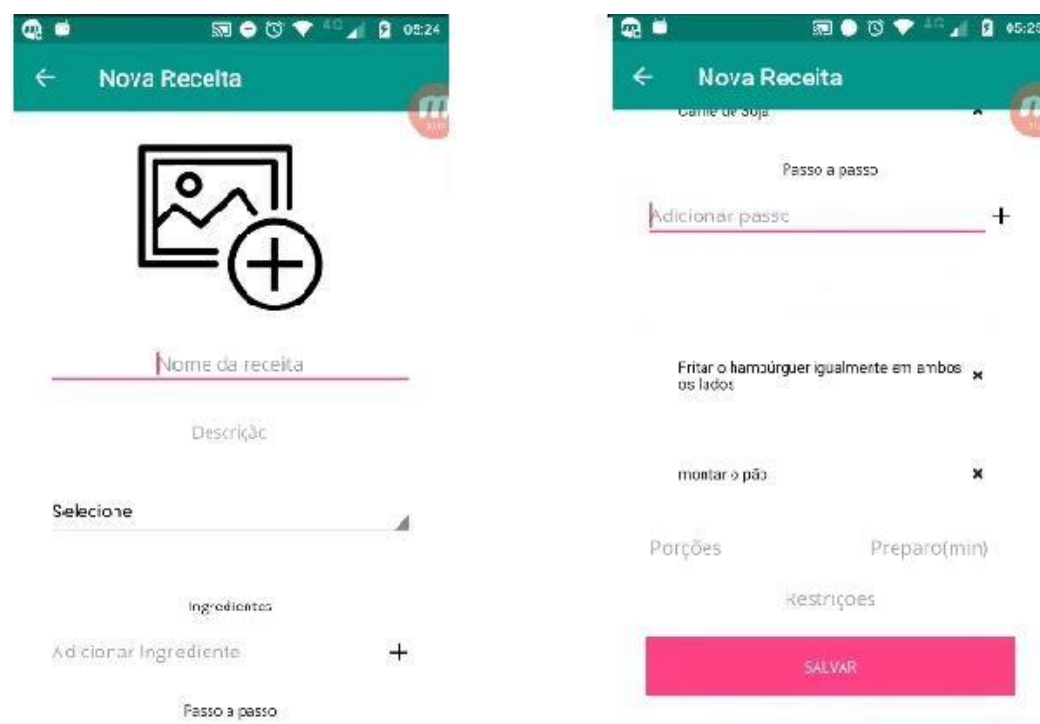

Figura 7. Tela de cadastro de receitas

\section{Conclusões e trabalhos futuros}

Com o decorrer do processo de pesquisa foi possível identificar que, apesar de assuntos relacionados a restrições alimentares estarem cada vez mais presentes na mídia e no conhecimento popular, isso não acontece em relação a plataformas colaborativas que atendam a esse tipo de público. A falta de comunicação e visibilidade de restaurantes acessíveis é um dos principais problemas para pessoas com restrições alimentares. Foi possível verificar que a maioria dos entrevistados relatou problemas relacionados à dificuldade de acesso a informações e do desconhecimento de restaurantes que atendam a sua restrição.

A fim de dar continuidade a plataforma, pretende-se integrar a plataforma com redes sociais já conhecidas, como Facebook e Twitter, com o intuito de ampliar a comunidade do aplicativo. Após, pretende-se criar uma nova seção no aplicativo, onde profissionais da área da nutrição poderão se comunicar com os usuários da plataforma e também será implementado o apoio à pessoas que necessitam seguir uma certa dieta, por exemplo, alguém que não pode ingerir glúten, mas que necessita de uma alimentação rica em proteínas. Por fim, será realizada a validação e avaliação do sistema, através de cenários de teste em ambiente controlado, e em conjunto com questionários e entrevistas, a fim de averiguar a aceitação da plataforma, como descrito na Seção 4. 


\section{Referências}

Bricks, L. Reações adversas aos alimentos na infância: intolerância e alergia alimentar: atualização. Pediatria, p. 176-185, 1994. Disponível em: $<$ http://www.luzimarteixeira.com.br/wp-content/uploads/2009/11/atualizacao-emintolerancia-alimentar.pdf $>$ Acesso em: 14 de jun. 2016.

Faria, L; Giuliani, A; Pizzinatto, N; Pizzinatto, A; A aplicabilidade do modelo estendido ao consumo da Teoria Unificada da Aceitação e Uso da Tecnologia (UTAUT2) no Brasil: Uma avaliação do modelo a partir de usuários de internet em smartphones. Rev. ADM. UFSM, Santa Maria, v. 7, Número 2, p. 332-348, 2014. Disponível em: < https://periodicos.ufsm.br/reaufsm/article/viewFile/13088/pdf $>$. Acesso em: $10 \mathrm{de}$ mai 2017.

Filho, R; Scalco, F; Pinto, A. Alergia à proteína do leite de vaca. Rev. Med. Minas Gerais, p. 374-380, 2014. Disponível em: <http://rmmg.org/esportar-pdf/1658/v24n3a13.pdf $>$ Acesso em: 14 de jun. 2016.

Gasparin, F; Carvalho, J; Araujo, S. Alergia à Proteína do Leite de Vaca Versus Intolerância à Lactose: As Diferenças e Semelhanças. Saúde e Pesquisa, v. 3, n. 1, 2001. Disponível em: $<$ http://periodicos.unicesumar.edu.br/index.php/saudpesq/article/view/1069> Acesso em: 14 de jun. 2016.

Google. Material Design. Disponível em: <https://design.google.com/articles/>. Acesso em: 31 de mar. 2016.

Metz, G.; Burks, W. Food allergies; ACP Medicine. pg. 1-8, 2009. Disponível em: $<$ http://www.medicinanet.com.br/m/conteudos/acp-

medicine/5318/alergias_alimentares_\%E2\%80\%93_gregory_m_metz_a_wesley_bur ks.htm> Acesso em: 11 de maio $201 \overline{6}$.

Nunes, M; Barros, R; Moreira, P; Moreira, A; Almeida, M. Alergia alimentar. PORTUGAL. Ministério da educação e ciência, 2012. Disponível em: $<$ https://www.dgs.pt/documentos-e-publicacoes/alergias-alimentares-jpg.aspx $>$ Acesso em: 14 de jun. 2016.

Pérez-Machado, M; Ashwood, P; Thomson, M; Latcham, F; Sim, R; Walker-Smith, J; Murch, S. Reduced transforming growth factor- $\beta 1$ - producing T cells in the duodenal mucosa of children with food allergy. European jornal of immunology, v. 33, n. 8, p. 2307-2315, 2003. Disponível em: $<$ http://onlinelibrary.wiley.com/doi/10.1002/eji.200323308/full $>$ Acesso em: 15 de jun. 2016.

Pimentel, M; Gerosa, M; Filippo, D; Raposo, A; Fuks, H; Lucena, C. Modelo 3C de Colaboração para o desenvolvimento de Sistemas Colaborativos, $3^{\circ}$ SBSC, 2006. Disponível em: <https://webserver2.tecgraf.pucrio.br/ abraposo/pubs/SBSC2006/07_Pimentel_Modelo3C.pdf $>$ Acesso em 01 de abr. 2016.

Porto, C; Thofehrn, M; Sousa, A; Cecagno, D. Experiência vivenciada por mães de crianças com intolerância à lactose. Família, Saúde e Desenvolvimento, v. 7, n. 3, 2005. Disponível em: <http://revistas.ufpr.br/refased/article/view/8032/5655> Acesso em: 15 de jun. 2016. 
Quintana, A. Uma análise sistemática das legislações vigentes no Brasil e no exterior referente a alimentos considerados isentos de glúten, 2011. 31 f. TCC (Graduação) Curso de Direito, Pontifícia Universidade Católica do Rio Grande do Sul, Porto Alegre, 2011. Disponível em: $<$ http://www3.pucrs.br/pucrs/files/uni/poa/direito/graduacao/tcc/tcc2/trabalhos2011_ 1/ana_quintana.pdf> Acesso em: 20 de ago. 2016.

Sanz, M. Inmunidad del tracto intestinal: procesamiento de antígenos. Alergologia e Inmunologia Clinica, Madrid, v. 16, n. 2, p. 58-62, 2001. Acesso em: 27/08/2016

Satyanarayanan, M. (2001) Pervasive Computing: vision and challenges, IEEE Personal Communications, [S.1.], v. 8, p. 10-17, 2001. Disponível em: $<$ http://www.cs.cmu.edu/ aura/docdir/pcs01.pdf>. Acesso em: 09 de dez. 2016.

Spiekermann, S. General Aspects of Location-Based Services. In: SCHILLER, J; VOISARD, A. Location-based Services. Elsevier, 2004. p. 15 - 32. Acesso em: 08 de jun. 2016.

Square Inc. Retrofit, 2013. Disponível em: $<$ http://square.github.io/retrofit/>. Acesso em: 31 de mar. 2016.

Tumas R; Cardoso, A. Como conceituar, diagnosticar e tratar a intolerância à lactose. Revista Brasileira de Clínica e, v. 34, n. 1, p. 13-20, 2008. Disponível em: $<$ http://www.moreirajr.com.br/revistas.asp?id_materia=3697\&fase=imprime $>$ Acesso em: 15 de jun. 2016.

Vieira, C. Guia de Diagnóstico e Tratamento de Alergia à Proteína do Leite de Vaca. São Paulo, SP: Suporte, 2004.

Weiser, M. The computer for the 21 st century, Scientific American, v. 265, n. 3, p. 94104, 1991. Disponível em: <https://www.ics.uci.edu/ corps/phaseii/WeiserComputer21stCentury-SciAm.pdf>. Acesso em: 09 de dez. 2016 